
$\$$ Research Square
Preprints are preliminary reports that have not undergone peer review.
They should not be considered conclusive, used to inform clinical practice, or referenced by the media as validated information.

\title{
Genetic diversity among queen bee, worker bees and larvae in terms of retrotransposon movements
}

Levent Mercan

Ondokuz May?s Üniversitesi: Ondokuz Mayis Universitesi

Cihat Erdem Bulbul

Ondokuz May?s Üniversitesi: Ondokuz Mayis Universitesi

Sevgi Marakli ( $\nabla$ smarakli@yildiz.edu.tr)

Yildiz Technical University Faculty of Arts and Sciences: Yildiz Teknik Universitesi Fen Edebiyat Fakultesi https://orcid.org/0000-0001-5796-7819

\section{Research Article}

Keywords: Barley, Honeybee, Mobile genetic elements, Nikita, Sukkula

Posted Date: November 30th, 2021

DOI: https://doi.org/10.21203/rs.3.rs-1088751/v1

License: () (1) This work is licensed under a Creative Commons Attribution 4.0 International License. Read Full License

Version of Record: A version of this preprint was published at Genetic Resources and Crop Evolution on January 15th, 2022. See the published version at https://doi.org/10.1007/s10722-021-01331-0. 


\section{Abstract \\ Objective}

Honeybee (Apis mellifera L.) is a model organism, contributing significant effect on global ecology by pollination and examining due to its social behaviour.

\section{Methods}

In this study, barley-specific Sukkula and Nikita retrotransposons were analysed using IRAP (Inter-Retrotransposon Amplification Polymorphism) marker technique, and the relationships between retrotransposon movements and development were also investigated in three different colonies of the Caucasian bee (Apis mellifera caucasica). Furthermore, transposon sequences belonging to Apis mellifera, Bombus terrestris, Triticum turgidum and Hordeum vulgare were also examined to figure out evolutionary relationships.

\section{Results}

For this purpose, a queen bee, five worker bees, and five larvae from each colony were studied. Both retrotransposons were found in all samples in three colonies with different polymorphism ratios (0-100\% for Nikita and 0-67\% for Sukkula). We also determined polymorphisms in queen-worker (0-83\% for Nikita, 0-63\% for Sukkula), queen-larvae (0-83\% for Nikita, 0-43\% for Sukkula) and worker-larvae comparisons (0-100\% for Nikita, 0-63\% for Sukkula) in colonies. Moreover, close relationships among transposons found in plant and insect genomes as a result of in silico evaluations to verify experimental results.

\section{Conclusion}

This work could be one of the first studies to analyse plant-specific retrotransposons' movements in honeybee genome. Results are expected to understand evolutionary relationships in terms of horizontal transfer of transposons among kingdoms.

\section{Introduction}

The vast majority of all known animal species are members of the Arthropoda phylum, and the class Insecta is the most significant class of Arthropods. Almost $80 \%$ of animal species defined in the world are found in the class Insecta (Stork et al. 2015; Zhang 2013). Honeybee (A. mellifera L.) is an economically and ecologically critical social insect for human beings. In the beehive, female bees (queen and worker) originate from fertilized eggs and males (drone) from unfertilized eggs. If larvae are specially fed with royal jelly, it turns into queen bees and produces thousands of eggs in a day while if not feed with royal jelly, they become sterile workers. Therefore, the bee is a very suitable model organism to study the relationship between nutrition (environment) and genetic structure (The Honeybee Genome Sequencing Consortium 2006).

Transposons, mobile genetic elements, are divided into two groups including Class I (RNA transposons or retrotransposons) and Class II (DNA transposons). They move via copy-paste and cut-paste mechanism, respectively. They constitute different portions of animal genomes (3-60\%). This ratio is very high in plant genomes (up to 90\%) (Canapa et al. 2015). It is reported that the genome size of the honeybee is $236 \mathrm{Mb}$, and approximately $3 \%$ of the genome consist of transposons. Although there are many retrotransposons in the honeybee genome, there are little pieces of evidence for active transposable elements (The Honeybee Genome Sequencing Consortium 2006).

In this study, we aimed to investigate the presence and movements of barley-specific Nikita and Sukkula retrotransposons by using IRAP marker technique and evaluation the polymorphisms in different colonies at different developmental stages in honeybee genome for the first time. Moreover, we obtained transposon sequences belonging to different genomes from NCBI to figure out the evolutionary relationships.

\section{Materials And Methods}

Honeybee materials

In this study, three colonies of Apis mellifera caucasica were selected from the beekeeping unit of Department of Animal Sciences of Faculty of Agriculture in Ondokuz Mayıs University. Genomic DNA of a total of 33 honeybee samples consisting of 11 samples from each colony (1 queen, 5 workers, and 5 larvae) were isolated according to Evans et al. (2013). The concentration and quality of genomic DNA were determined using a spectrophotometer and $1 \%$ (w/v) agarose gel.

IRAP analyses

Barley-specific Nikita and Sukkula retrotransposons' movements were analysed by IRAP molecular marker technique. Primer sequences were 5'ACCCCTCTAGGCGACATCC3' for Nikita and 3'GGAACGTCGGCATCGGGCTG5' for Sukkula (Leigh et al. 2003). IRAP-PCR was carried out in $25 \mu L$ of the reaction mixture containing $6.5 \mu \mathrm{L}$ of nuclease-free $\mathrm{dH}_{2} \mathrm{O}, 12.5 \mu \mathrm{L}$ of MasterMix (DreamTaq Green PCR Master Mix, Thermo Scientific ${ }^{\mathrm{TM}}$ ), $2 \mu \mathrm{L}$ of $10 \mu \mathrm{M} / \mu \mathrm{L}$ primer $(0.8 \mu \mathrm{M} / \mu \mathrm{L}), 4 \mu \mathrm{L}$ of $20 \mathrm{ng} / \mu \mathrm{L}(3.2 \mathrm{ng} / \mu \mathrm{L})$ template genomic DNA. Final concentrations were indicated in parentheses. The amplification conditions were as follows: one initial denaturation step $\left(95^{\circ} \mathrm{C}\right.$ for $\left.3 \mathrm{~min}\right)$ followed by 35 cycles of denaturation $\left(95^{\circ} \mathrm{C}\right.$ for $\left.30 \mathrm{~s}\right)$, annealing $\left(54^{\circ} \mathrm{C}\right.$ for $\left.30 \mathrm{~s}\right)$ and extension $\left(72^{\circ} \mathrm{C}\right.$ for $\left.1 \mathrm{~min}\right)$. The reaction was completed by a final extension step $\left(72^{\circ} \mathrm{C}\right.$ for $\left.5 \mathrm{~min}\right)$. PCR products were resolved on $1 \%$ agarose gel $(\mathrm{w} / \mathrm{v})$ in $1 \mathrm{X}$ TBE $(\mathrm{Tris}-$ Boric acid-EDTA) at $120 \mathrm{~V}$ for $120 \mathrm{~min}$. Then, agarose gel photographed on a UV transilluminator and band profiles belonging to samples were evaluated. 
Calculations of polymorphism

Band profiles of queen bees, worker bees, and larvae were examined one by one for each sample, and monomorphic and polymorphic bands were determined. Polymorphism rates among samples were calculated using the Jaccard similarity index. Jaccard's similarity index could be calculated using the formula:

$N_{\mathrm{AB}} /\left(N_{\mathrm{AB}}+N_{\mathrm{A}}+N_{\mathrm{B}}\right)$; where $N_{\mathrm{AB}}$ is the number of bands shared by two samples, $N_{\mathrm{A}}$ represents amplified fragments in sample A, and $N_{\mathrm{B}}$ represents amplified fragments in sample B (Jaccard 1908).

Evolutionary relationships among transposons

Transposon sequences of related species Apis mellifera and Bombus terrestris in addition to Nikita and Sukkula sequences belonging to Triticum turgidum and Hordeum vulgare were examined to evaluate evolutionary relationships among these species and verify our IRAP results. For this purpose, sequences were retrieved from NCBI (www.ncbi.nlm.nih.gov) and a phylogenetic tree was constructed by using these sequences via MEGA X (Kumar et al. 2018) with following parameters: neighbour-joining (NJ) method (Saitou and Nei 1987) with the p-distance model (Nei and Kumar 2000), and even bootstrap test (1000 replicates) (Felsenstein 1985).

\section{Results}

Nikita showed higher polymorphism than Sukkula

Barley-specific Nikita retrotransposon was identified in queen bees, worker bees, and larvae. As a result of IRAP-PCR, samples displayed a band profile in the range of 200-1500 bp (Fig. 1).

Nikita retrotransposon showed a very high percentage of polymorphism (0-100\%) in all samples. Polymorphism levels are 0-71\% among the members of the first colony, $0-60 \%$ among the members of the second colony and $0-100 \%$ among the members of the third colony. Polymorphism rates also detected among queens $(25-33 \%)$, workers $(0-100 \%)$ and larvae $(0-83 \%)$ in three colonies (Table 1$)$

Moreover, polymorphism rates were also detected within colonies. Polymorphism rates of queen-workers and queen-larvae were the same in the first colony (0$71 \%$ ). Polymorphism ratio was also determined as $14-71 \%$ for workers-larvae. In the second colony, there was $0-50 \%$ polymorphisms for queen-workers, $0-57 \%$ for queen-larvae. However, this rate increased by $67 \%$ for workers-larvae. The most polymorphic patterns were determined in the third colony. Polymorphism rates for queen-worker and queen-larvae were found to be the same but higher (0-83\%) compared to other colonies. Besides, $0-100 \%$ of polymorphism rates were determined as a result of comparison between workers and larvae.

Similar to Nikita, barley-specific Sukkula retrotransposon was also identified in the queen, workers and larvae, ranging from 250 to 1500 (Fig. 2 ). When compared to Nikita, Sukkula indicated lower polymorphism percentages among samples.

In general, polymorphism rates among individuals of all colonies for Sukkula retrotransposon were determined in the range of 0-67\%. However, polymorphism rates among samples in the first colony were $0-43 \%$ while $0-63 \%$ for the second and third colonies. When compared to queens, workers and larvae in three colonies, $14-57 \%, 20-50 \%$ and $0-43 \%$ ratios were observed, respectively (Table 2 ). 


\begin{tabular}{|c|c|c|c|c|c|c|c|c|c|c|c|c|c|c|c|c|c|c|c|c|c|c|c|}
\hline & & \multicolumn{11}{|c|}{ FIRST COLONY } & \multicolumn{11}{|c|}{ SECOND COLONY } \\
\hline & & Q1 & W1 & W2 & W3 & W4 & W5 & L1 & L2 & L3 & L4 & L5 & Q2 & W1 & W2 & w3 & W4 & W5 & L1 & L2 & L3 & L4 & L5 \\
\hline \multirow{11}{*}{$\begin{array}{l}\text { FIRST } \\
\text { COLONY }\end{array}$} & Q1 & 0 & & & & & & & & & & & & & & & & & & & & & \\
\hline & W1 & 20 & 0 & & & & & & & & & & & & & & & & & & & & \\
\hline & W2 & 20 & 0 & 0 & & & & & & & & & & & & & & & & & & & \\
\hline & w3 & 20 & 0 & 0 & 0 & & & & & & & & & & & & & & & & & & \\
\hline & W4 & 20 & 0 & 0 & 0 & 0 & & & & & & & & & & & & & & & & & \\
\hline & W5 & 20 & 0 & 0 & 0 & 0 & 0 & & & & & & & & & & & & & & & & \\
\hline & L1 & 43 & 29 & 29 & 29 & 29 & 29 & 0 & & & & & & & & & & & & & & & \\
\hline & L2 & 43 & 29 & 29 & 29 & 29 & 29 & 0 & 0 & & & & & & & & & & & & & & \\
\hline & L3 & 43 & 29 & 29 & 29 & 29 & 29 & 0 & 0 & 0 & & & & & & & & & & & & & \\
\hline & L4 & 43 & 29 & 29 & 29 & 29 & 29 & 0 & 0 & 0 & 0 & & & & & & & & & & & & \\
\hline & L5 & 43 & 29 & 29 & 29 & 29 & 29 & 0 & 0 & 0 & 0 & 0 & & & & & & & & & & & \\
\hline \multirow{11}{*}{$\begin{array}{l}\text { SECOND } \\
\text { COLONY }\end{array}$} & Q2 & 57 & 43 & 43 & 43 & 43 & 43 & 14 & 14 & 14 & 14 & 14 & 0 & & & & & & & & & & \\
\hline & W1 & 20 & 0 & 0 & 0 & 0 & 0 & 29 & 29 & 29 & 29 & 29 & 43 & 0 & & & & & & & & & \\
\hline & w2 & 67 & 50 & 50 & 50 & 50 & 50 & 63 & 63 & 63 & 63 & 63 & 57 & 50 & 0 & & & & & & & & \\
\hline & w3 & 20 & 0 & 0 & 0 & 0 & 0 & 29 & 29 & 29 & 29 & 29 & 43 & 0 & 50 & 0 & & & & & & & \\
\hline & W4 & 40 & 20 & 20 & 20 & 20 & 20 & 43 & 43 & 43 & 43 & 43 & 33 & 20 & 40 & 20 & 0 & & & & & & \\
\hline & W5 & 40 & 20 & 20 & 20 & 20 & 20 & 43 & 43 & 43 & 43 & 43 & 33 & 20 & 40 & 20 & 0 & 0 & & & & & \\
\hline & L1 & 20 & 0 & 0 & 0 & 0 & 0 & 29 & 29 & 29 & 29 & 29 & 43 & 0 & 50 & 0 & 20 & 20 & 0 & & & & \\
\hline & L2 & 43 & 29 & 29 & 29 & 29 & 29 & 0 & 0 & 0 & 0 & 0 & 14 & 29 & 63 & 29 & 43 & 43 & 29 & 0 & & & \\
\hline & L3 & 43 & 29 & 29 & 29 & 29 & 29 & 0 & 0 & 0 & 0 & 0 & 14 & 29 & 63 & 29 & 43 & 43 & 29 & 0 & 0 & & \\
\hline & L4 & 43 & 29 & 29 & 29 & 29 & 29 & 0 & 0 & 0 & 0 & 0 & 14 & 29 & 63 & 29 & 43 & 43 & 29 & 0 & 0 & 0 & \\
\hline & L5 & 43 & 29 & 29 & 29 & 29 & 29 & 0 & 0 & 0 & 0 & 0 & 14 & 29 & 63 & 29 & 43 & 43 & 29 & 0 & 0 & 0 & 0 \\
\hline \multirow{11}{*}{$\begin{array}{l}\text { THIRD } \\
\text { COLONY }\end{array}$} & Q3 & 43 & 29 & 29 & 29 & 29 & 29 & 0 & 0 & 0 & 0 & 0 & 14 & 29 & 63 & 29 & 43 & 43 & 29 & 0 & 0 & 0 & 0 \\
\hline & W1 & 40 & 20 & 20 & 20 & 20 & 20 & 43 & 43 & 43 & 43 & 43 & 33 & 20 & 40 & 20 & 0 & 0 & 20 & 43 & 43 & 43 & 43 \\
\hline & w2 & 40 & 20 & 20 & 20 & 20 & 20 & 43 & 43 & 43 & 43 & 43 & 33 & 20 & 40 & 20 & 0 & 0 & 20 & 43 & 43 & 43 & 43 \\
\hline & W3 & 67 & 50 & 50 & 50 & 50 & 50 & 63 & 63 & 63 & 63 & 63 & 57 & 50 & 0 & 50 & 40 & 40 & 50 & 63 & 63 & 63 & 63 \\
\hline & W4 & 50 & 33 & 33 & 33 & 33 & 33 & 50 & 50 & 50 & 50 & 50 & 63 & 33 & 20 & 33 & 50 & 50 & 33 & 50 & 50 & 50 & 50 \\
\hline & W5 & 40 & 20 & 20 & 20 & 20 & 20 & 43 & 43 & 43 & 43 & 43 & 33 & 20 & 40 & 20 & 0 & 0 & 20 & 43 & 43 & 43 & 43 \\
\hline & L1 & 43 & 29 & 29 & 29 & 29 & 29 & 0 & 0 & 0 & 0 & 0 & 14 & 29 & 63 & 29 & 43 & 43 & 29 & 0 & 0 & 0 & 0 \\
\hline & L2 & 50 & 33 & 33 & 33 & 33 & 33 & 29 & 29 & 29 & 29 & 29 & 17 & 33 & 50 & 33 & 20 & 20 & 33 & 29 & 29 & 29 & 29 \\
\hline & L3 & 50 & 38 & 38 & 38 & 38 & 38 & 13 & 13 & 13 & 13 & 13 & 25 & 38 & 50 & 38 & 50 & 50 & 38 & 13 & 13 & 13 & 13 \\
\hline & L4 & 20 & 0 & 0 & 0 & 0 & 0 & 29 & 29 & 29 & 29 & 29 & 43 & 0 & 50 & 0 & 20 & 20 & 0 & 29 & 29 & 29 & 29 \\
\hline & L5 & 57 & 43 & 43 & 43 & 43 & 43 & 38 & 38 & 38 & 38 & 38 & 29 & 43 & 33 & 43 & 33 & 33 & 43 & 38 & 38 & 38 & 38 \\
\hline
\end{tabular}

The highest polymorphism rates were identified for queen-larvae (43\%) in the first colony. Also, there was $20 \%$ polymorphism for queen-workers and $29 \%$ for worker-larvae. In the second colony, the lowest polymorphism rate was observed for queen-larvae comparison (14\%). On the other hand, higher polymorphism was detected for queen-workers (33-57\%) and workers-larvae (0-63\%). These rates were $0-38 \%$ for queen-larvae, $43-63 \%$ for queen-workers and $20-63 \%$ for workers-larvae in the third colony.

In silico analyses showed similarities among retrotransposons in insect and plant genomes

A phylogenetic tree was constructed by using 53 different sequences (Fig. 3). All positions containing gaps and missing data were eliminated (complete deletion option). There were a total of 105 positions in the final dataset. We observed that all sequences were clustered into two groups. Most of $A$. mellifera 
sequences were found in the first group. Moreover, $A$. mellifera and $B$. terrestris sequences were found in one clade while Sukkula sequences formed a second clade. In the second group, similar to the first one, A. mellifera, B. terrestris and Sukkula sequences were observed. In addition, Nikita sequences were also determined in this group.

\section{Discussion}

Transposable elements can be inherited via vertical transfer which is genetic transfer from ancestral to descendant species (Markova and Mason-Gamer 2015; Wallau et al. 2016). On the other hand, many evidence also showed that these sequences move horizontally (Zhang et al. 2020). Phylogenetic relatedness among species is an important factor for horizontal transfer of transposons (HTT). There are many studies in which a retrotransposon specific to a particular plant is detected in a different plant. In one of these studies, Nikita and Sukkula retrotransposons were studied in the aniseed. Polymorphism was not found in both retrotransposons but their presence in the aniseed genome was determined (Marakli 2018). In another study, these two retrotransposons were identified in two varieties of black pine (Pinus nigra var. pyramidata and Seneriana). Sukkula retrotransposon showed 0-76\% polymorphism in pyramidata variety while no polymorphism was detected in Seneriana variety. Similarly, Nikita polymorphism (0-56\%) was detected only in pyramidata variety (Marakli et al. 2019).

In addition to closely related species, HTT could also observe in distantly related taxa (Gao et al., 2018; Metzger et al., 2018; Zhang et al., 2020). Concordant with this opinion, we identified barley-specific retrotransposons in chicken genome for the first time in our previous study (Mercan et al. 2021). In this presented study, barley-specific Nikita and Sukkula movements were also analysed by using IRAP marker technique in bees with different growth capabilities due to feeding in different periods. Higher polymorphism ratios were determined in bee genome (0-100\% for Nikita and 0-67\% for Sukkula) among queen, workers and larvae. Moreover, similar sequences were identified among transposons in Apis mellifera, Bombus terrestris, Triticum turgidum and Hordeum vulgare genomes. These results could be supported by Meyerowitz (2002), reporting a common ancestor for plants and animals.

In honeybee genome, there are very few transposons including 15 partial sequences of a Copia family sequence with highly distorted copies, 6 partial sequences matching the coding BEL 12 element of Anopheles gambiae, and 3 highly degraded copies of a DIRS retrotransposon (Eiglmeier et al. 2005; Goodwin et al. 2004). Moreover, 11 LTR and 7 non-LTR retrotransposon residues in Drosophila were also found in honeybee genome (Kaminker et al. 2002). Other study was carried out by Gillespie et al. (2006). They suggested that ribosomal DNA units of honeybees contain active non-LTR retrotransposons of the $R 2$ family. They also reported that although active $R 2$ non-LTR retrotransposons were identified, $R 1$ line was not found in honeybee genome. Elsik et al. (2014) also determined the presence of copia, $R 2$ and / retrotransposons together with mariner and piggyBactransposons in the genome of the honeybee. Similarly, Wang et al. (2017) reported that queen bees and drones contain mariner, piggyBac, R2, copia, Bel-Pao and / transposons but worker bees only contain mariner, piggyBac and $R 2$ transposons.

There are many studies related to the effect of retrotransposon movements on species identification (Leśniowska-Nowak et al. 2021), organ differentiation (Ramos et al. 2011; Zhu et al. 2012) and abiotic/biotic stress (Ghonaim et al. 2021) conditions by using retrotransposon-based molecular markers. Most of these studies were performed in plant genomes because transposons constitute most of plant genomes.

\section{Conclusions}

To our best knowledge, there is no investigation related to plant-specific retrotransposons in the honeybee. The findings could be preliminary results to understand the difference between Nikita and Sukkula retrotransposons' movements related to retrotransposon effects on an important species for humanity's future. Deep sequencing of honeybee genome will provide better understand the relationships among different organisms in different species.

\section{Declarations}

\section{Conflict of Interest}

We certify that there is no conflict of interest with any financial organization regarding the material discussed in the manuscript.

\section{Acknowledgement}

This paper contained data from the Master thesis of the second author (Cihat Erdem Bulbul).

\section{References}

1. Canapa A, Barucca M, Biscotti MA, Forconi M, Olmo E (2015) Transposons, genome size, and evolutionary insights in animals. Cytogenet Genome Res 147:217-239

2. Eiglmeier K, Wincker P, Cattolico L, Anthouard V, Holm I, Eckenberg R, Quesneville H, Jaillon O, Collins FH, Weissenbach J, Brey PT, Roth CW (2005) Comparative analysis of BAC and whole genome shotgun sequences from an Anopheles gambiae region related to Plasmodium encapsulation. Insect Biochem Mol Biol 35:799-814

3. Elsik CG, Worley KC, Bennett AK, Beye M, Camara F, Childers CP, de Graaf DC, Debyser G, Deng J, Devreese B (2014) Finding the missing honey bee genes: lessons learned from a genome upgrade. BMC Genom 15:86

4. Evans JD, Schwarz RS, Chen YP, Budge G, Cornman RS, De la Rua P, de Miranda JR, Foret S, Foster L, Gauthier L, Gisder S, Jarosch A, Kucharski R, Lopez D, Man-Lun C, Moritz RFA, Maleszka R, Muñoz I, Pinto MA, Genersch E (2013) Standard methods for molecular research in Apis mellifera. J Apic Res 52:1-54

5. Felsenstein J (1985) Confidence limits on phylogenies: An approach using the bootstrap. Evolution 39:783-791 
6. Gao D, Chu Y, Xia H, Xu C, Heyduk K, Abernathy B, Ozias-Akins P, Leebens-Mack JH, Jackson SA (2018) Horizontal transfer of non-LTR retrotransposons from arthropods to flowering plants. Mol Biol Evol 35:354-364

7. Ghonaim MM, Mohamed HI, Omran AA (2021) Evaluation of wheat (Triticum aestivum L.) salt stress tolerance using physiological parameters and retrotransposon-based markers. Genet Resour Crop Evol 68:227-242

8. Gillespie J, Johnston J, Cannone J, Gutell R (2006) Characteristics of the nuclear (18S, 5.8 S, 28S and 5S) and mitochondrial (12S and 16S) rRNA genes of Apis mellifera (Insecta: Hymenoptera): structure, organization, and retrotransposable elements. Insect Mol Biol 15:657-686

9. Goodwin T, Poulter R, Lorenzen M, Beeman R (2004) DIRS retroelements in arthropods: identification of the recently active TcDirs1 element in the red flour beetle Tribolium castaneum. Mol Genet Genom 272:47-56. https://doi.org/10.1007/s00438-004-1028-2

10. Jaccard P (1908) Nouvelles recherches sur la distribution florale. Bull de la Soc Vaud des Sci Nat 44:223-270

11. Kaminker JS, Bergman CM, Kronmiller B, Carlson J, Svirskas R, Patel S, Frise E, Wheeler DA, Lewis SE, Rubin GM (2002) The transposable elements of the Drosophila melanogaster euchromatin: a genomics perspective. Genome Biol 3:research0084-1

12. Kumar S, Stecher G, Li M, Knyaz C, Tamura K (2018) MEGA X: Molecular evolutionary genetics analysis across computing platforms. Mol Biol Evol 35:1547-1549

13. Leigh F, Kalendar R, Lea V, Lee D, Donini P, Schulman AH (2003) Comparison of the utility of barley retrotransposon families for genetic analysis by molecular marker techniques. Mol Genet Genom 269:464-474

14. Leśniowska-Nowak J, Okoń S, Wieremczuk A (2021) Molecular diversity analysis of genotypes from four Aegilops species based on retrotransposonmicrosatellite amplified polymorphism (REMAP) markers. Cereal Res Commun 49:37-44

15. Marakli S (2018) Transferability of barley retrotransposons (Sukkula and Nikita) to investigate genetic structure of Pimpinella anisum L. Marmara Fen Bilim Derg 30:299-304

16. Marakli S, Calis A, Gozukirmizi N (2019) Determination of barley-specific retrotransposons' movements in Pinus nigra ssp. pallasiana varieties: pyramidata and Seneriana. Russ J Genet 55:71-78

17. Markova DN, Mason-Gamer RJ (2015) The role of vertical and horizontal transfer in the evolutionary dynamics of PIF-like transposable elements in Triticeae. PLoS ONE 10:e0137648

18. Mercan L, Bulbul CE, Bilgi F, Marakli S (2021) Determination of plant-specific retrotransposons in chicken. Turkish J Vet Anim Sci. https://doi.org/10.3906/vet-2102-56

19. Metzger MJ, Paynter AN, Siddall ME, Goff SP (2018) Horizontal transfer of retrotransposons between bivalves and other aquatic species of multiple phyla. Proc Natl Acad Sci 115:E4227-E4235

20. Meyerowitz EM (2002) Plants compared to animals: the broadest comparative study of development. Science 295:1482-1485

21. Nei M, Kumar S (2000) Molecular Evolution and Phylogenetics. Oxford University Press

22. Ramos KS, Montoya-Durango DE, Teneng I, Nanez A, Stribinskis V (2011) Epigenetic control of embryonic renal cell differentiation by $L 1$ retrotransposon. Birth Defects Res Part A Clin Mol Teratol 91:693-702

23. Saitou N, Nei M (1987) The neighbor-joining method: A new method for reconstructing phylogenetic trees. Mol Biol Evol 4:406-425

24. Stork NE, McBroom J, Gely C, Hamilton AJ (2015) New approaches narrow global species estimates for beetles, insects, and terrestrial arthropods. Proc Natl Acad Sci 112:7519-7523

25. The Honeybee Genome Sequencing Consortium (2006) Insights into social insects from the genome of the honeybee Apis mellifera. Nature 443:931-949

26. Wallau GL, Capy P, Loreto E, Le Rouzic A, Hua-Van A (2016) VHICA, a new method to discriminate between vertical and horizontal transposon transfer: Application to the mariner family within Drosophila. Mol Biol Evol 33:1094-1109

27. Wang W, Ashby R, Ying H, Maleszka R, Forêt S (2017) Contrasting sex-and caste-dependent piRNA profiles in the transposon depleted haplodiploid honeybee Apis mellifera. Genome Biol Evol 9:1341-1356

28. Zhang HH, Peccoud J, Zhang XG, Gilbert C (2020) Horizontal transfer and evolution of transposable elements in vertebrates. Nature Commun 11:1-10

29. Zhang Z-Q (2013) Animal biodiversity: An update of classification and diversity in 2013. In: Zhang, Z-Q. (Ed.) Animal Biodiversity: An Outline of Higherlevel Classification and Survey of Taxonomic Richness (Addenda 2013). Zootaxa 3703:5-11. https://doi.org/10.11646/zootaxa.3703.1.3

30. Zhu W, Kuo D, Nathanson J, Satoh A, Pao GM, Yeo GW, Bryant SV, Voss R, Gardiner DM, Hunter T (2012) Retrotransposon long interspersed nucleotide element-1 (LINE-1) is activated during salamander limb regeneration. Dev Growth Differ 54:675-685

\section{Tables}

Due to technical limitations, Table 1 is only available as a download in the Supplemental Files section.

\section{Figures}




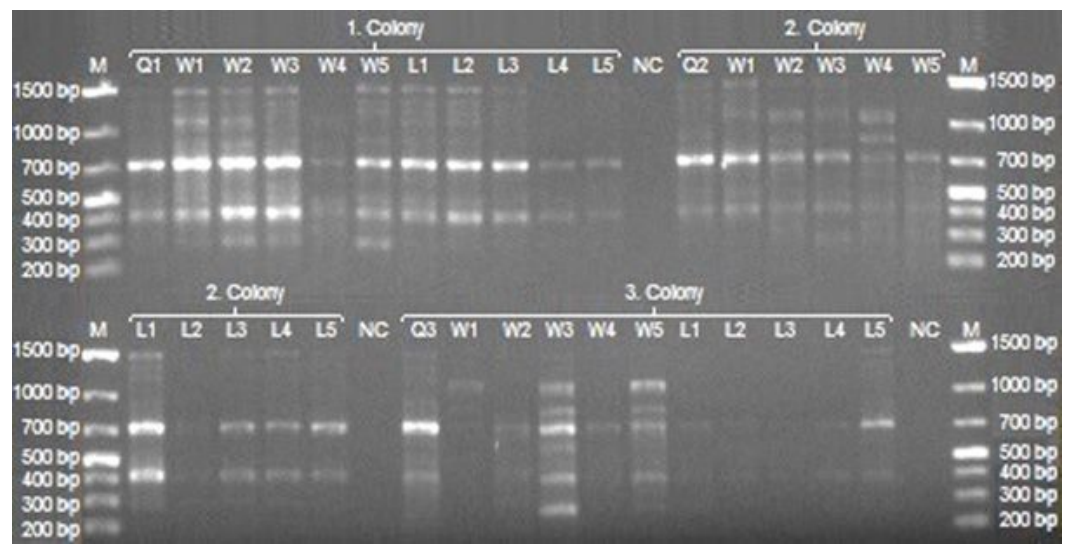

Figure 1

IRAP-PCR results of Nikita retrotransposon (M, marker; Q, queen; W, worker; L, larva; NC, Negative control).

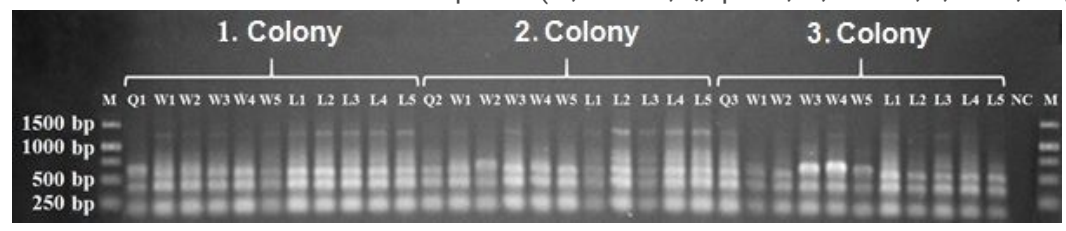

Figure 2

IRAP-PCR results of Sukkula retrotransposon (M, marker; Q, queen; W, worker; L, larva; NC, Negative control).

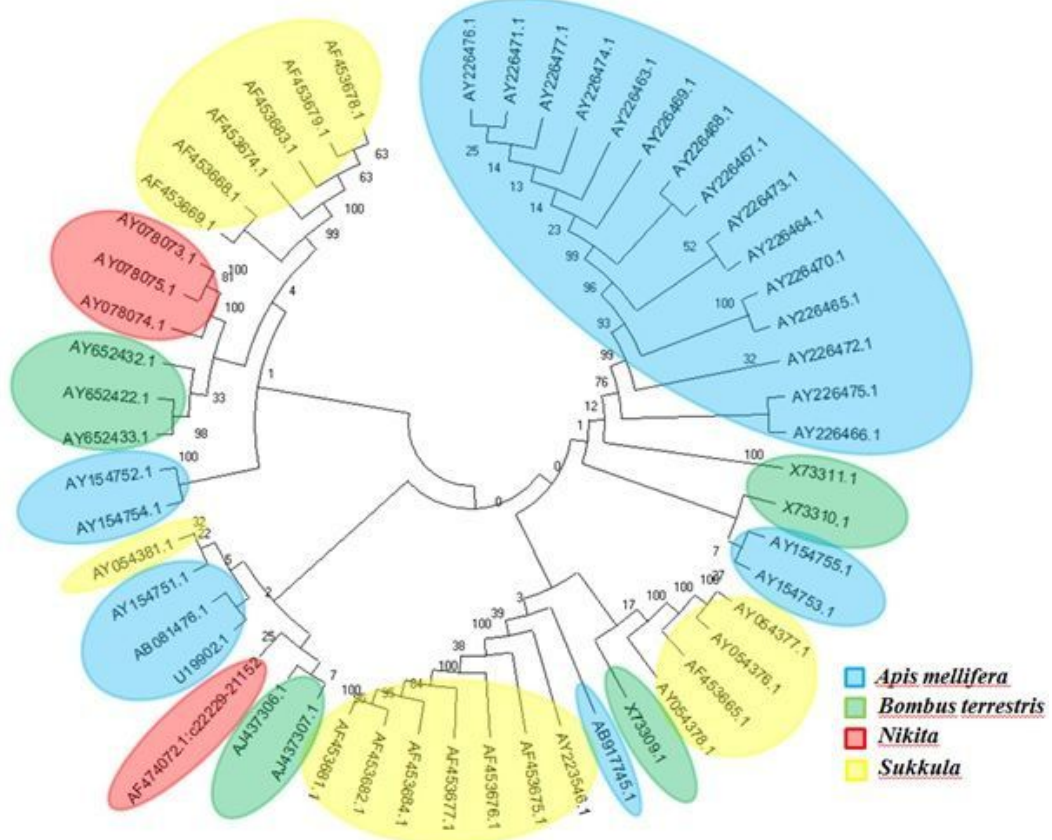

Figure 3

Phylogenetic tree analysis of transposons belonging to insect and plant species.

\section{Supplementary Files}

This is a list of supplementary files associated with this preprint. Click to download.

- Table1.docx 